\title{
Adolescent physical activity: the role of parental social support and the level of physical activity. Social Support and Physical Activity of Parents and Adolescents.
}

Edina Maria de Camargo ( $\nabla$ edinacamargo@gmail.com )

Universidade Federal do Parana https://orcid.org/0000-0003-2127-2606

Jose Francisco López-Gil

Universidade de Murcia

Thiago Silva Piola

Universidade Federal do Parana

Jorge Augusto Pinto Silva Mota

Universidade do Porto Faculdade de Desporto

Wagner de Campos

Universidade Federal do Paraná

Research article

Keywords: motor activity, parents, adolescents, social support

Posted Date: October 29th, 2019

DOI: https://doi.org/10.21203/rs.2.16556/v1

License: (c) (i) This work is licensed under a Creative Commons Attribution 4.0 International License.

Read Full License 


\section{Abstract}

Background: To verify the relationship between the level of moderate to vigorous physical activity of parents and that social support with the level of moderate to vigorous physical activity in adolescents.

Methods: Cross-sectional study that selected 1390 (59.6\% female) adolescents. The questionnaires IPAQ, QAFA and ASAFA were used. Binary logistic regression was used to test the relationship between the study variables. The direction and magnitude measurement were verified.

Results: In relation to girls, the fact of receiving incentives from parents $(\mathrm{OR}=1.589-\mathrm{Cl} 95 \%=1.060-2.382)$ and having parents/legal guardians who meet the vigorous moderate physical activity recommendations $(\mathrm{OR}=2.038-\mathrm{Cl} \mid 95 \%=1.424-2.918)$ was associated with meeting the vigorous moderate physical activity recommendations. Regarding boys, the support of parents related to transportation (OR=1.741 $\mathrm{Cl} 95 \%=1.114-2.719)$, parents who comment on physical activity $(\mathrm{OR}=0.440-\mathrm{Cl} \mid 95 \%=0.266-0.729)$ and parents who meet the vigorous moderate physical activity recommendations $(\mathrm{OR}=2.739-\mathrm{Cl} 95 \%=1.700$ 4.14) were associated with meeting the recommendations for adolescents.

Conclusions: The social support from parents increased to practice physical activity contributes to adolescents chances of achieving moderate to vigorous physical activity recommendation. Adolescents who have physically active parents (who comply moderate to vigorous physical activity recommendations) are almost twice as likely to comply with the recommendations.

\section{Background}

The increase in the prevalence of physical inactivity, both in developed and developing countries, is of great concern since it is the fourth leading cause of death in the world ${ }^{1}$, besides increasing the risk of suffering from 35 chronic diseases ${ }^{2}$. It is estimated that, on average, every fourth one in the world population is not active enough ${ }^{3,4}$. Therefore, if current trends continue, the WHO (World Health Organization) goal of achieving an insufficient $10 \%$ relative reduction in physical activity (PA) in the population by 2025 will not be achieved ${ }^{4,5}$. In Brazilian adolescents, physical inactivity in free time reaches $54.3 \% 6,7$. The factors that can influence these data are very varied ${ }^{8-13}$, including sociodemographic, economic or social/family support indicators, among others ${ }^{14,15}$.

In this sense, numerous national and international studies indicate that the level of social support (SS) in the family context, as well as in the peer group, is linked to higher levels of PA in adolescents ${ }^{15-19}$. In addition, the fact that parents perform PA at the same time is a good model for children to perform $\mathrm{PA}^{20-}$ 22. Furthermore, a longitudinal study that included 13.000 students observed that PA performed by parents showed an association with that performed by their children ${ }^{23}$.

To date, the studies have presented the association of the PA level of parents or legal guardians and SS in isolation ${ }^{14,15,21,23}$. The present study seeks to investigate the chance that an adolescent has to comply 
with the MVPA (vigorous moderate physical activity) recommendations if parents or legal guardians also comply with it; in parallel, it investigates the SS received from parents or legal guardians to practise PA (encourage, practice together, transport, assist and comment on how well the adolescent is doing his/her $\mathrm{PA})$.

With these results it will be possible to verify the meaning of the variables mentioned about the level of MVPA in adolescents. Once investigated, this gap can contribute to a better understanding of how to maximize the levels of MVPA in adolescents, with the support and example coming from parents (father, mother, caregiver).

Thus, the aim of this study was to verify the relationship between the level of MVPA of parents or legal guardians and that of SS with the level of MVPA in adolescents.

\section{Methods}

The study followed the standards of research involving human beings of the National Health Council (resolution number 466/2012), having been approved by the Research Ethics Committee of the Federal University of Paraná (CAAE: 98133218.8.0000.0102) and authorized by adolescents' the parents or legal guardians by means of a free and informed consent form.

This is a cross-sectional study conducted in 2018 with a representative sample of adolescents aged 15 to 17 enrolled in high school in the public school.

For the preliminary sample calculation, an association of $\mathrm{OR}=1.49$ was considered between SS and $\mathrm{PA}^{24}$, a prevalence of being insufficiently active of $50 \%{ }^{25}$, a confidence level of $95 \%(a=0.05)$ with a power of $80 \%(\beta=0.20)$, resulting in a minimum sample of 804 subjects. However, an increase of $30 \%$ was considered for possible losses and refusals, which estimated a minimum sample required for the study of 965 subjects. The sample was selected from the process of sampling by multiple stages, conglomerates, in three stages: 1 st stage - all state schools were stratified according to each of the nine administrative regions of the city of Curitiba; 2 nd stage - a draw was made among the nine administrative regions of the city, being two of them the one chosen; 3rd stage - a simple random selection of a class of each year was performed, according to the number of students, separated by sex, required for a given region. Finally, all students in each class were invited to participate in the study.

A total of 2506 adolescents were evaluated, but those who presented physical and/or cognitive limitations that could restrict the practice of PA (informed by the school) $(n=12)$ and were 18 years old $(n$ $=125$ ) were excluded. Adolescents who did not present the informed consent form signed by their parents or legal guardians $(n=104)$, those who refused to participate in the study, or missed the day of collection $(n=56)$, as well as those who answered the questionnaires incorrectly $(n=66)$ and those who did not answer the PA level $(n=753)$ when the questionnaire was sent home, were considered as sample loss. Thus, the analytical sample of the study was 1390 adolescents. 
Statistical analyses carried out subsequently showed that this sample could identify statistically significant ratios above 1.36 and below 0.73 , considering a power of $80 \%(\beta=20 \%)$, a confidence level of $95 \%(a=5 \%)$ and considering a prevalence of $34 \%$ of adolescents with low SS and who did not meet the minimum recommendations for PA.

\section{Physical Activity - Parents / Legal Guardians and Adolescents}

The MVPA level of parents or legal guardians was measured through the IPAQ questionnaire - short version (International Physical Activity Questionnaire), in which parents or legal guardians reported "how many days a week" and "how long a day" they practiced MVPA, over a normal week ${ }^{26}$. The time dedicated to each PA practice (leisure and displacement) per week was categorized according to the current recommendations of MVPA practice ${ }^{26}$.

The PA level of adolescents was evaluated by the Physical Activity Questionnaire for Adolescents (QAFA) ${ }^{27}$. This questionnaire was first developed in the checklist format by Sallis et al, $1996^{28}$ for North American adolescents, translated and adapted for Brazilian adolescents by Farias-Júnior et al, 2012.The questionnaire consists of a list of 24 moderate to vigorous physical activities, with the possibility of adolescents adding activities beyond those listed. In Brazilian adolescents, the questionnaire showed good reproducibility $\left(\mathrm{CCl}=0.88 ; \mathrm{Cl}_{95 \%}=0.84-0.91\right)$ and concurrent validity when compared to 24 -hour recall $(r=0.62 ; p<0.001)^{27}$. To analyse the MVPA level, it was classified as "it meets the recommendations" ( $\geq 420$ minutes per week of MVPA practice) and "it does not meet" ( $<420$ minutes per week of MVPA practice).

\section{SS received from parents or legal guardians for the practice of PA}

The SS of the adolescents' parents or legal guardians to practise PA was measured by the scale of 5 items Social Support for Physical Activity Practice for Adolescents (ASAFA), which has satisfactory consistency (SS of parents $a \geq 0.77$ and IFC $\geq 0.83)^{29}$. Adolescents reported the frequency (never $=1$, rarely $=2$, frequently $=3$, always $=4$ ) with which parents offered some type of SS for the practice of PA (encourage, practice, transport, assist, comment) during a typical or normal week ${ }^{29}$. For purposes of analysis, and with the aim of ensuring comparability with similar studies ${ }^{30}$, the response options "rarely" and "frequently" were grouped and classified as "sometimes". Thus, the weekly frequency categories of SS were classified as never, sometimes and always. For the creation of the median variable, we considered the sum of the values assigned to each item ( 5 to 20 points) and computed an overall score of parents' SS, categorized by the median: "low SS" and "high SS".

\section{Sociodemographic Information and Health}


Gender was self-reported ("male", "female") and age was calculated from the date of birth (informed by the adolescent) subtracted from the date of data collection and divided by 365 , resulting in: "15 years", "16 years", "17 years". The nutritional status was calculated with the measured data on body mass and size $\left(\mathrm{kg} / \mathrm{m}^{2}\right)$ and adolescents were classified as "not excess of weight" and "excess of weight" education level of the main family breadwinner and his/her socioeconomic status (SES) were evaluated with a standardized questionnaire ${ }^{32}$. The Education level was classified as: Elementary School, Secondary School or higher Education levels. SES was classified into three categories: "low" (class C+D), "medium" (class B1+B2) and "high" (class A1+A2) (ABEP, 2016) ${ }^{32}$.

\section{Data Analysis}

After having identified the data distribution by the Kolmogorov-Smirnov test, descriptive statistics were used to distribute absolute and relative frequencies and the chi-square test $\left(\chi^{2}\right)$ was used to verify differences in proportions in relation to sex and recommended levels of MVPA in adolescents. Binary logistic regression was used to test, in an exploratory manner, the relationship between the study variables. Three blocks of analysis were established to this aim. Firstly, the sociodemographic variables and health were included: gender, age, BMI, the main breadwinner's education level and SES. In the second block it was inserted the SS received from parents/legal guardians for the practice of PA, while in the third block the information on MVPA of parents/legal guardians was included. The variables that presented $p<0.20$ in this exploratory analysis were inserted and tested again in the model. The results were tested according to gender (male and female), using the command "divided file". To avoid bias related to the complex sample selection process (cluster stratification), the association analyses were corrected by the complex design using the SPSS software version 23.0 "complex sample" command.

\section{Results}

The sample was composed by 1390 adolescents (59.6\% female) and their respective parents/ legal guardians. Tables 1 and 2 show the variables of the study stratified by gender, where: BMI $(p=0.001)$, NSE $(p=0.015)$ and the level of MVPA of parents $(p=0.021)$ showed significant differences. Likewise, when stratified by adolescents who "comply with the MVPA recommendations" and "do not comply", we found that the main breadwinner's education level $(p=0.004)$ and level of MVPA of parents $(p=0.000)$ were significant.

In relation to girls, the fact of receiving incentives from parents $\left(\mathrm{OR}=1.589-\mathrm{Cl}_{95 \%}=1.060-2.382\right)$ and having parents/legal guardians who meet the MVPA recommendations $\left(\mathrm{OR}=2.038-\mathrm{Cl}_{95 \%}=1.424-\right.$ 2.918) was associated with meeting the MVPA recommendations. Regarding boys, the support of parents related to transportation $\left(\mathrm{OR}=1.741-\mathrm{Cl}_{95 \%}=1.114-2.719\right)$, parents who comment on $\mathrm{PA}(\mathrm{OR}=0.440-$ $\left.\mathrm{Cl}_{95 \%}=0.266-0.729\right)$ and parents who meet the MVPA recommendations $\left(\mathrm{OR}=2.739-\mathrm{Cl}_{95 \%}=1.700-\right.$ 4.14) were associated with meeting the recommendations for adolescents (Table 3 ). 
Table 1. Sociodemographic information and health, social support and data on physical activity stratified by sex $(n=1390)$.

BMI: body mass index; SES: socioeconomic status; SS: Social Support; MVPA: moderate to vigorous physical activity; *Statistically significant for the chi-square test for continuity correction; $\mathbb{\Delta}$ Statistically significant for the linear association by chi-square test; $p<0.05$.

Table 2. Sociodemographic information and health, social support and level of physical activity of parents / guardians, stratified by the recommendation of physical activity for adolescents $(n=1390)$.

BMI: body mass index; SES: socioeconomic status; SS: Social Support; MVPA: moderate to vigorous physical activity; *Statistically significant for the chi-square test for continuity correction; $\mathbb{Q}$ Statistically significant for the linear association by chi-square test; $p<0.05$.

Table 3. Association of the sociodemographic information, the social support and the level of physical activity of parents/legal guardians with regards to recommended MVPA levels in adolescents $(n=1390)$.

SS: Social Support; MVPA: moderate to vigorous physical activity; *Statistically significant for the test; $p<0,05$.

\section{Discussion}

Numerous studies indicate that the level of SS in the family context, as well as recommended levels of PA from parents or legal guardians are linked to higher levels of PA in adolescents ${ }^{15-23}$. However, scientific literature has analysed these variables independently. Aiming at this, the present study sought to investigate the variables in the same sample of adolescents, in order to analyse how much the fact of having parents or legal guardians physically active and receiving their support for the practice of PA could contribute to achieve the recommendations of MVPA in adolescents.

In the present study, for girls, the fact of receiving incentives from parents and having parents/legal guardians who comply with the MVPA recommendations was associated with complying the MVPA recommendations. In the case of boys, the support of parents related to transportation and the fact of having parents who meet the MVPA recommendations were associated with meeting recommended MVPA levels. A systematic review ${ }^{33}$ published in 2014 consistently observed that adolescents who received greater SS reported higher levels of PA, reinforcing the importance of this support in adolescent participation in $\mathrm{PA}^{33}$. However, the low number of studies made it impossible to analyse the association among different types of SS, PA intensities and adolescent characteristics, such as gender and age ${ }^{33}$.

On the importance of SS "encouraging" (encouraged you to do PA) for girls and "transporting" (transported or provided transportation to get you to the place of your PA) for boys, other studies also noted how positive these reinforcements can be in the adolescent phase. 
Piola et $\mathrm{al}^{34}$, in the city of Curitiba (Brazil), in a study of adolescents found that the fact that parents "always" commented positively on the activities was absolutely associated with the practice of PA (OR = $\left.2.60-\mathrm{Cl}_{95 \%}=1.01-6.10\right)$. Variations in associations between different types and sources of SS can also be observed according to the age of adolescents.

In this sense, Duncan et al ${ }^{35}$ observed that older adolescents have greater perception from family members when this comes in the form of encouragement and talk about PA. Similarly, Yao and Rhodes ${ }^{36}$ also noted that parental encouragement was the SS most strongly related to their children's PA. In the study by Prado et $\mathrm{al}^{13}$, the fact of always receiving positive reinforcement from parents was associated with PA of boys. In the same way, there are other studies that show encouragement as a way of SS most commonly reported by adolescents, regardless of their source ${ }^{33-36}$. Most of the types of SS explored in this study did not present a significant association with the practice of PA. This finding was also observed in the multivariate analyses by Fermino et $\mathrm{al}^{24}$, Prado et $\mathrm{al}^{30}$ and Piola et $\mathrm{al}^{34}$, who also did not observe significant associations between most types of SS and PA.

In a systematic review ${ }^{37}$ of studies that examined the Both children's and parents' PA, conducted in countries with high development index (United States, United Kingdom, Australia, Canada, France and Portugal) all with cross-sectional design, it was showed that fathers' MVPA was associated with that of children, as well as the participation in vigorous activities of children was associated with the practice of VPA (vigorous physical activity) of parents ${ }^{37}$. For mothers, the practice of MPA (moderate physical activity) was associated with that of children ${ }^{37}$. Both associations were confirmed for weekdays and weekends ${ }^{37}$. The physical activities reported by parents in their childhood and adolescence were also associated with higher levels of PA among adolescents ${ }^{38}$. Adolescents with physically active parents in the past and currently, were six times $\left(\mathrm{OR}=6.670-\mathrm{Cl}_{95 \%}=1.940-2.790\right)$ more likely to be physically active compared to adolescents whose parents/legal guardians were not physically active in the past ${ }^{38}$. Therefore, it seems necessary to understand these parental constructions that measured PA since childhood $^{37-41}$.

Complying with the MVPA recommendations established for parents contributes to increasing the chance of adolescents complying with the MVPA recommendation by almost twice as much. Bound together, these findings demonstrate that the regular practice of parents' PA, combined with the support they provide to their children for the practice of PA, are important factors not only for adolescents in PA, but also for the continued practice. When close people are present and value their behavior, adolescents' selfesteem tends to rise; thus, it increases their perception of self-efficacy $3,14,15,37,38$; what can contribute, inexorably, to higher levels of PA $3,14,15,37,38$. Consequently, more studies are needed to assess the relationship between SS and PA over a broader age group. Some points should be considered when interpreting the results of this study. The fact that the sample is formed only with students from the public school system makes it impossible to extrapolate the results to higher classes. However, the representative sample and the statistical analyses ensure an interpretation of the data for large populations from public schools. 
The results confirm the importance of the family environment for adolescent's PA. It indicates that the influence of the family environment (receiving support from parents or legal guardians and having active parents or legal guardians) in the dynamic behaviour of adolescents, operates, in a way, through the attitudes they receive from parents or legal guardians, such as support and especially the example of being physically active. Parental or legal guardian encouragement can have a direct influence on the active participation of adolescents, since it can lead adolescents to participate in a more automatic process, establishing routines.

\section{Conclusion}

The SS (encouraging, transporting, commenting) from parents to practice PA contributes to adolescents' chances of achieving MVPA recommendations. Furthermore, adolescents who have physically active parents/legal guardians (who comply with the MVPA recommendations) are almost twice as likely to comply with the recommendations. For boys, the association values are higher when compared to girls. The repeated encouragement and forms of support from parents/legal guardians, in addition to the example of being physically active, can initiate and build confidence so that the perceived behavioural control is improved and becomes a routine in the adolescents' lifestyle.

\section{Abbreviations}

PA = Physical Activity

SS = Social Support

MVPA = Vigorous Moderate Physical Activity

$\mathrm{IPAQ}=$ International Physical Activity Questionnaire

QAFA = Physical Activity Questionnaire for Adolescents

ASAFA = Social Support for Physical Activity Practice for Adolescents

SS = Socioeconomic Status

VPA $=$ Vigorous Physical Activity

MPA = Moderate Physical Activity

\section{Declarations}

\section{Ethics approval and consent to participate (attached statements)}

The study followed the standards of research involving human beings of the National Health Council (resolution number 466/2012), having been approved by the Research Ethics Committee of the Federal 
University of Paraná (CAAE: 98133218.8.0000.0102) and authorized by adolescents' the parents or legal guardians by means of a free and informed consent form.

\section{Consent for publication}

Not Applicable

\section{Availability of data and material}

The datasets generated and/or analysed during the current study are not publicly available, the data are part of a doctoral thesis, which will be defended in February 2020. But are available from the corresponding author on reasonable request.

The authors declare that all data supporting the findings of this study are available within the article.

\section{Competing interests}

The authors declare that they have no competing interests.

\section{Funding}

EMC- This work was supported by the Coordination of Improvement of Higher Education Personnel Brazil (CAPES) - Financing Code 001. JAPSM - It was supported by grants: FCT: SFRH / BSAB / 142983/2018 and UID / DTP / 00617/2019 as well as the Santander Universities 2018 Scholarship Program

\section{Authors' contributions}

EMC, Responsible for all aspects of the work. JFLG, Writing the manuscript. TSP, Writing the manuscript. JAPSM, Relevant critical content review. WC, Relevant critical content review. All authors read and approved the final manuscript.

\section{Acknowledgements}

Not Applicable.

\section{References}

1. World Health Organization Global health risks: mortality and burden of disease attributable to selected major risks. Geneva, Switzerland: World Health Organization; 2009. 62 p. 
2. Booth FW, Roberts CK, Thyfault JP, Ruegsegger GN, Toedebusch RG. Role of Inactivity in Chronic Diseases: Evolutionary Insight and Pathophysiological Mechanisms. Physiol Revi. 2017.97(4):1351402.

3. Sallis JF, Bull F, Guthold R, et al. Progress in physical activity over the Olympic quadrennium. Lancet. 2016. 388(10051):1325-36.

4. Guthold R, Stevens GA, Riley LM, Bull FC. Worldwide trends in insufficient physical activity from 2001 to 2016: a pooled analysis of 358 population-based surveys with 1.9 million participants. Lancet Glob Health. 2018. 6(10):e1077-1086.

5. World Health Organization (WHO). Global action plan on physical activity 2018-2030: more active people for a healthier world. Genova: WHO. 2018.

6. Ekelund U, Brage S, Froberg K et al. TV viewing and physical activity are independently associated with metabolic risk in children: the European Youth Heart Study. PLoS Med. 2006. 3(12): e488.

7. Cureau FV, Silva TLN, Bloch KV et al. ERICA: Leisure-time physical inactivity in Brazilian adolescents. Rev Saúde Públ. 2016.50(1):1-11.

8. Ding D, Lawson KD, Kolbe-Alexander TL et al. The economic burden of physical inactivity: a global analysis of major non-communicable diseases. Lancet. 2016. 388(10051): 1311-1324.

9. Lear SA, Hu W, Rangarajan S et al. The effect of physical activity on mortality and cardiovascular disease in 130000 people from 17 high-income, middle-income, and low-income countries: the PURE study. Lancet. 2017. 390(10113):2643-54.

10. Lee IM, Shiroma EJ, Lobelo F, Puska P, Blair SN, Katzmarzyk PT. Effect of physical inactivity on major non-communicable diseases worldwide: an analysis of burden of disease and life expectancy. Lancet. 2012. 380(9838):219-229.

11. Ortega FB, Ruiz JR, Castillo MJ, Sjöström M. Physical fitness in childhood and adolescence: a powerful marker of health. Int J Obes. 2008;32(1):1-11.

12. Skrede T, Steene-Johannessen J, Anderssen SA, Resaland GK, Ekelund U. The prospective association between objectively measured sedentary time, moderate-to-vigorous physical activity and cardiometabolic risk factors in youth: a systematic review and meta-analysis: Physical activity and metabolic health. Obes Rev. 2019.20(1):55-74

13. Tarp J, Child A, White T, et al. Physical activity intensity, bout-duration, and cardiometabolic risk markers in children and adolescents. Int J Obes. 2018.42(9):1639-50.

14. Garcia JM, Sirard JR, Deutsch NL, Weltman A. The influence of friends and psychosocial factors on physical activity and 447 screen time behavior in adolescents: a mixed-methods analysis. J Behav Med. 2016.39:610-23.

15. Bauman AE, Reis RS, Sallis JF, Wells JC, Loos RJ, Martin BW. Correlates of physical activity: why are some people physically active and others not? Lancet. 2012. 380(9838):258-71.

16. Van der horst K, Paw MJ, Twisk JW, Van Mechelen W. A brief review on correlates of physical activity and sedentariness in youth. Med Sci Sports Exerc. 2007.39(8):1241-50. 
17. Sallis J, Taylor WC, Dowda M, Freedson PS, Pate RR. Correlates of vigorous physical activity for children in grades 1 through 12: comparing parent-reported and objectively measured physical activity. Ped Exer Sci. 2002.14(1):30-44.

18. Raudsepp L. The relationship between socio-economic status,parental support and adolescent physical activity. Acta Paediatr.2006.95:93-8.

19. Salvy SJ, Haye K, Bowker JC, Hermans RC. Influence of peersand friends on children's and adolescents' eating and activitybehaviors. Physicol Behav. 2012.106:369-78.

20. Laird Y, Fawkner S, Kelly P, McNamee L, Niven A. The role of 450 social support on physical activity behaviour in adolescent girls: a systematic review and meta-analysis. Int J Behav Nutr Phys Act. 2016.13:79.

21. Cheng LA, Mendonça G, Farias Júnior JC. Physical activity in adolescents: analysis of the social influence of parents and friends. J Pediatr. 2014. 90(1):35-41.

22. Yao CA, Rhodes RE. Parental correlates in child and adolescent physical activity: a meta-analysis. Int J Behav Nutr Phys Act. 2015. 12:10.

23. Ornelas IJ, Perreira KM, Ayala GX. Parental influences on adolescent physical activity: a longitudinal study. Int J Behav Nutr Phys Act. 2007.4:3.

24. Fermino RC, Rech CR, Hino AA, Rodriguez Anez CR,Reis RS. Physical activity and associated factors in highschool adolescents in Southern Brazil. Rev Saude Publ. 2010.44(6):986-95.

25. Barbosa Filho VC, Campos W, Bozza R, Lopes AS. The prevalence and correlates of behavioral risk factors for cardiovascular health among Southern Brazil adolescents: a cross-sectional study. BMC Pediatrics. 2012.12:130.

26. WHO. Global recommendations on physical activity for health. Genova: World Health Organization, 2010.

27. Farias Júnior JC de, Lopes A da S, Mota J, Santos MP, Ribeiro JC, Hallal PC. Validade e reprodutibilidade de um questionário para medida de atividade física em adolescentes: uma adaptação do Self-Administered Physical Activity Checklist. Rev Bras Epidemiol. 2012.15(1):198210.

28. Sallis JF, Strilmiller P k, Harsha DW, et al. Validation of interviewer-and self- administered physical activity checklists for fifth grade students. Off J Am Coll Sport Med.1996. 28: 840-851.

29. Farias Júnior JC, Mendonça G, Florindo AA, Barros MVG. Reliability and validity of a physical activity social support assessment scale in adolescents - ASAFA Scale. Rev bras epidemiol. 2014.17(2): 355-370.

30. Prado CV, Lima AV, Fermino RC, Rodriguez-Anez CR, Reis RS. Social support and physical activity in adolescents from public schools: the importance of family and friends. Cad Saúde Pública. 2014. 30:827-38.

31. WHO. WHO child growth standards: length/height for age, weight-for-age, weight-for-length, weightfor-height and body mass index-for-age, methods and development: World Health Organization; 2006. 
32. Associação Brasileira de Empresas de Pesquisa (ABEP) (2016). Critério de Classificação Econômica São Paulo, Brasil: ABEP.

33. Mendonca G, Cheng LA, Melo EN, Farias Junior JC. Physical activity and social support in adolescents: a systematic review. Health educ res. 2014. 29:822-39

34. Piola TS, Bacil EDA, lumi PW, Camargo EC et al. Sexual Maturation, social support and physical activity in adolescents. Cuadernos de Psicología Del Deporte. 2019. 19(3):CPD3.

35. Duncan SC, Duncan TE, Strycker LA. Sources and types of social support in youth physical activity. Health psychology: official journal of the Division of Health Psychology. Health Psychol. 2005. 24(1):3-10.

36. Yao CA, Rhodes RE. Parental correlates in child and adolescent physical activity: a meta-analysis. Int J Behav Nutr Phys Act. 2015. 12:10.

37. Neshteruk CD, Nezami BT, Nino-Tapias G, Davison KK, Ward DS. The influence of fathers on children's physical activity: A review of the literature from 2009 to 2015. Prev Med. 2017. 102:12-19.

38. Christofaro DGD, Andersen LB, Andrade SM, et al. Adolescents' physical activity is associated with previous and current physical activity practice by their parents. J. Pediatr. 2018. 94(1): 48-55.

39. Timperio AF, Van Stralen MM, Brug J, Bere E, et al. Direct and indirect associations between the family physical activity environment and sports participation among 10-12 year-old European children: testing the EnRG framework in the ENERGY project. Int J Behav Nutr Phys Act. 2013. 10:15.

40. Beets MW, Cardinal BJ, Alderman BL. Parental social support and the physical sctivity-related behaviors of youth: a review. Health Educ Behav. 2010. 37:621-44.

41. Laird Y, Fawkner S, Kelly P, McNamee L, Niven A. The role of social support on physical activity behaviour in adolescent girls: a systematic review and meta-analysis. Int J Behav Nutr Phys Act. 2016. 13:79.

\section{Tables}

Table 1. Sociodemographic information and Health, social support and data on physical activity stratified by sex $(n=1390)$. 


\begin{tabular}{|c|c|c|c|c|c|c|c|c|}
\hline \multicolumn{2}{|c|}{ Sociodemographic Information and Health } & \multicolumn{2}{|c|}{ Boys } & \multicolumn{2}{|c|}{ Girls } & \multirow[b]{2}{*}{ p } & \multicolumn{2}{|c|}{ TOTAL } \\
\hline & & $\mathrm{n}$ & $\%$ & $\mathrm{n}$ & $\%$ & & $\mathrm{n}$ & $\%$ \\
\hline \multirow[t]{3}{*}{ Age } & 15 & 175 & 37.7 & 289 & 62.3 & 0.090 & 464 & 100.0 \\
\hline & 16 & 203 & 40.5 & 298 & 59.5 & & 501 & \\
\hline & 17 & 184 & 43.3 & 241 & 56.7 & & 425 & \\
\hline \multirow[t]{2}{*}{ BMl } & Not Excess of Weight & 469 & 38.8 & 741 & 61.2 & $0.001^{*}$ & 1210 & 100.0 \\
\hline & Excess of Weight & 93 & 51.7 & 87 & 48.3 & & 180 & \\
\hline \multirow[t]{3}{*}{ The main breadwinner's education level } & Elementary School & 217 & 40.3 & 322 & 59.7 & & 539 & 100.0 \\
\hline & Secondary School & 192 & 38.8 & 303 & 61.2 & 0.490 & 495 & \\
\hline & Higher Education levels & 153 & 43.0 & 203 & 57.0 & & 356 & \\
\hline \multirow[t]{3}{*}{ SES } & Low SES & 93 & 35.8 & 167 & 64.2 & & 260 & 100.0 \\
\hline & Medium SES & 348 & 40.1 & 520 & 59.9 & $0.015 \rrbracket$ & 868 & \\
\hline & High SES & 121 & 46.2 & 141 & 53.8 & & 262 & \\
\hline \multicolumn{2}{|c|}{ SS Parents/Legal Guardians } & $\mathrm{n}$ & $\%$ & $\mathrm{n}$ & $\%$ & $\mathrm{p}$ & $\mathrm{n}$ & $\%$ \\
\hline \multirow[t]{3}{*}{ Encourage } & Never & 104 & 37.5 & 173 & 62.5 & & 277 & 100.0 \\
\hline & Sometimes & 313 & 40.3 & 463 & 59.7 & 0.168 & 776 & \\
\hline & Always & 145 & 43.0 & 192 & 57.0 & & 337 & \\
\hline \multirow[t]{3}{*}{ Practice together } & Never & 205 & 37.4 & 343 & 62.6 & & 548 & 100.0 \\
\hline & Sometimes & 288 & 42.0 & 398 & 58.0 & 0.060 & 686 & \\
\hline & Always & 69 & 44.2 & 87 & 55.8 & & 156 & \\
\hline \multirow[t]{3}{*}{ Transport } & Never & 268 & 40.5 & 394 & 59.5 & & 662 & 100.0 \\
\hline & Sometimes & 176 & 40.1 & 263 & 59.9 & 0.955 & 439 & \\
\hline & Always & 118 & 40.8 & 171 & 59.2 & & 289 & \\
\hline \multirow[t]{3}{*}{ Assist } & Never & 239 & 39.4 & 367 & 60.6 & & 606 & 100.0 \\
\hline & Sometimes & 235 & 40.4 & 346 & 59.6 & 0.355 & 581 & \\
\hline & Always & 88 & 43.3 & 115 & 56.7 & & 203 & \\
\hline \multirow[t]{3}{*}{ Comment } & Never & 209 & 38.7 & 331 & 61.3 & & 540 & 100.0 \\
\hline & Sometimes & 232 & 43.9 & 296 & 56.1 & 0.992 & 528 & \\
\hline & Always & 121 & 37.6 & 201 & 62.4 & & 322 & \\
\hline
\end{tabular}




\begin{tabular}{cc|ccccccc}
\multicolumn{2}{c|}{ Level of MVPA } & $\mathrm{n}$ & $\%$ & $\mathrm{n}$ & $\%$ & $\mathrm{p}$ & $\mathrm{n}$ & \\
\hline Parents/Legal Guardians & It does not meet & 411 & 42.5 & 557 & 57.5 & $0.021^{*}$ & 968 & 100.0 \\
& It meets & 151 & 35.8 & 271 & 64.2 & & 422 & \\
Adolescents & It does not meet & 367 & 39.4 & 564 & 60.6 & 0.296 & 931 & 100.0 \\
& It meets & 195 & 42.5 & 264 & 57.5 & & 459 \\
\hline
\end{tabular}

BMI: body mass index; SES: socioeconomic status; SS: Social Support; MVPA: moderate to vigorous physical activity; *Statistically

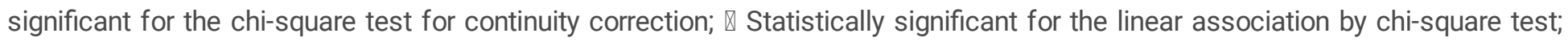
$p<0.05$.

Table 2. Sociodemographic information and health, social support and level of physical activity of parents / guardians, stratified by the recommendation of physical activity for adolescents $(n=1390)$. 


\begin{tabular}{|c|c|c|c|c|c|c|c|c|}
\hline \multirow{2}{*}{\multicolumn{2}{|c|}{ Sociodemographic Information and Health }} & \multicolumn{2}{|c|}{ It meets } & \multicolumn{3}{|c|}{ It does not meet } & \multicolumn{2}{|c|}{ TOTAL } \\
\hline & & $\mathrm{n}$ & $\%$ & $\mathrm{n}$ & $\%$ & $\mathrm{p}$ & $\mathrm{n}$ & $\%$ \\
\hline \multirow[t]{2}{*}{ Gender } & Masculino & 195 & 34.7 & 367 & 65.3 & 0.296 & 562 & 100.0 \\
\hline & Feminino & 264 & 31.9 & 564 & 68.1 & & 828 & \\
\hline \multirow[t]{3}{*}{ Age } & 15 & 164 & 35.3 & 300 & 64.7 & 0.349 & 464 & 100.0 \\
\hline & 16 & 157 & 31.3 & 344 & 68.7 & & 501 & \\
\hline & 17 & 138 & 32.5 & 287 & 67.5 & & 425 & \\
\hline \multirow[t]{2}{*}{$\mathrm{BMI}$} & Not Excess of Weight & 397 & 32.8 & 813 & 67.2 & 0.672 & 1210 & 100.0 \\
\hline & Excess of Weight & 62 & 34.4 & 118 & 65.6 & & 180 & \\
\hline \multirow[t]{3}{*}{ The main breadwinner's education level } & Elementary School & 188 & 34.9 & 351 & 65.1 & & 539 & 100.0 \\
\hline & Secondary School & 183 & 37.0 & 312 & 63.0 & $0.004 \rrbracket$ & 495 & \\
\hline & Higher Education levels & 88 & 24.7 & 268 & 75.3 & & 356 & \\
\hline \multirow[t]{3}{*}{ SES } & Low SES & 87 & 33.5 & 173 & 66.5 & & 260 & 100.0 \\
\hline & Medium SES & 284 & 32.7 & 584 & 67.3 & 0.975 & 868 & \\
\hline & High SES & 88 & 33.6 & 174 & 66.4 & & 262 & \\
\hline \multicolumn{2}{|c|}{ SS Parents/Legal Guardians } & $\mathrm{n}$ & $\%$ & $\mathrm{n}$ & $\%$ & $\mathrm{p}$ & $\mathrm{n}$ & $\%$ \\
\hline \multirow[t]{3}{*}{ Encourage } & Never & 105 & 37.9 & 172 & 62.1 & & 277 & 100.0 \\
\hline & Sometimes & 234 & 30.2 & 542 & 69.8 & 0.679 & 776 & \\
\hline & Always & 120 & 35.6 & 217 & 64.4 & & 337 & \\
\hline \multirow[t]{3}{*}{ Practice together } & Never & 185 & 33.8 & 363 & 66.2 & & 548 & 100.0 \\
\hline & Sometimes & 213 & 31.0 & 473 & 69.0 & 0.635 & 686 & \\
\hline & Always & 61 & 39.1 & 95 & 60.9 & & 156 & \\
\hline \multirow[t]{3}{*}{ Transport } & Never & 242 & 36.6 & 420 & 63.4 & & 662 & 100.0 \\
\hline & Sometimes & 120 & 27.3 & 319 & 72.7 & 0.112 & 439 & \\
\hline & Always & 97 & 33.6 & 192 & 66.4 & & 289 & \\
\hline \multirow[t]{3}{*}{ Assist } & Never & 209 & 34.5 & 397 & 65.5 & & 606 & 100.0 \\
\hline & Sometimes & 169 & 29.1 & 412 & 70.9 & 0.682 & 581 & \\
\hline & Always & 81 & 39.9 & 122 & 60.1 & & 203 & \\
\hline Comment & Never & 171 & 37.1 & 369 & 68.3 & & 540 & 100.0 \\
\hline
\end{tabular}




\begin{tabular}{|c|c|c|c|c|c|c|c|c|}
\hline & Sometimes & 171 & 32.4 & 357 & 67.6 & 0.184 & 528 & \\
\hline & Always & 117 & 36.3 & 205 & 63.7 & & 322 & \\
\hline \multicolumn{2}{|c|}{ Level of MVPA } & $\mathrm{n}$ & $\%$ & $\mathrm{n}$ & $\%$ & $\mathrm{p}$ & $\mathrm{n}$ & $\%$ \\
\hline \multirow[t]{2}{*}{ Parents/Legal Guardians } & It does not meet & 371 & 38.3 & 597 & 61.7 & $0.000 *$ & 968 & 100.0 \\
\hline & It meets & 88 & 20.9 & 334 & 79.1 & & 422 & \\
\hline
\end{tabular}

BMI: body mass index; SES: socioeconomic status; SS: Social Support; MVPA: moderate to vigorous physical activity; *Statistically

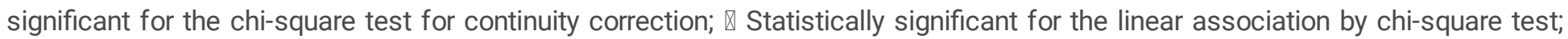
$p<0.05$.

Table 3. Association of the sociodemographic information, the social support and the level of physical activity of parents/legal guardians with regards to recommended MVPA levels in adolescents $(n=1390)$. 


\begin{tabular}{|c|c|c|c|c|c|c|c|c|c|c|c|c|c|c|c|c|}
\hline \multirow{3}{*}{\multicolumn{2}{|c|}{ Variables }} & \multicolumn{15}{|c|}{ RECOMMENDED LEVELS OF MVPA (420 minutes per week) } \\
\hline & & \multicolumn{5}{|c|}{ BOYS } & \multicolumn{5}{|c|}{ GIRLS } & \multicolumn{5}{|c|}{ TOTAL } \\
\hline & & $\mathrm{n}$ & $\%$ & OR & $\mathrm{Cl}_{95 \%}$ & $p$ & $n$ & $\%$ & OR & $\mathrm{Cl}_{95 \%}$ & $p$ & $n$ & $\%$ & OR & $\mathrm{Cl}_{95 \%}$ & p \\
\hline \multicolumn{17}{|l|}{ Age } \\
\hline 15 & & 175 & 37.7 & 1 & & & 289 & 62.3 & 1 & & & 464 & 100 & 1 & & \\
\hline 16 & & 203 & 40.5 & 1.463 & $\begin{array}{l}0.926- \\
2.311\end{array}$ & 0.103 & 298 & 59.5 & 1.329 & $\begin{array}{l}0.920- \\
1.920\end{array}$ & 0.130 & 501 & & 1.335 & $\begin{array}{l}1.006- \\
1.772\end{array}$ & $0.045^{\star}$ \\
\hline 17 & & 184 & 43.3 & 1.507 & $\begin{array}{l}0.945- \\
2.405\end{array}$ & 0.085 & 241 & 56.7 & 1.285 & $\begin{array}{l}0.869- \\
1.901\end{array}$ & 0.209 & 425 & & 0.969 & $\begin{array}{l}0.969- \\
1.745\end{array}$ & 0.080 \\
\hline \multicolumn{17}{|c|}{$\begin{array}{l}\text { The main readwinner's } \\
\text { education level }\end{array}$} \\
\hline Elementary & School & 217 & 40.3 & 1 & & & 322 & 59.7 & 1 & & & 539 & 100 & 1 & & \\
\hline Secondary S & School & 192 & 38.8 & 1.197 & $\begin{array}{l}0.781- \\
1.834\end{array}$ & 0.410 & 303 & 61.2 & 0.979 & $\begin{array}{l}0.690- \\
1.389\end{array}$ & 0.905 & 495 & & 1.024 & $\begin{array}{l}0.784- \\
1.337\end{array}$ & 0.863 \\
\hline \multicolumn{2}{|c|}{ Higher Education levels } & 153 & 43.0 & 1.959 & $\begin{array}{l}1.200- \\
3.196\end{array}$ & $0.007 *$ & 203 & 57.0 & 1.247 & $\begin{array}{l}0.829- \\
1.875\end{array}$ & 0.290 & 356 & & 1.490 & $\begin{array}{l}1.094- \\
2.029\end{array}$ & $0.011^{*}$ \\
\hline \multicolumn{17}{|c|}{ SS parents/legal } \\
\hline \multirow[t]{3}{*}{ Encourage } & Never & 104 & 37.5 & 1 & & & 173 & 62.5 & 1 & & & 277 & 100 & 1 & & \\
\hline & Sometimes & 313 & 40.3 & 0.970 & $\begin{array}{l}0.568- \\
1.658\end{array}$ & 0.912 & 463 & 59.7 & 1.589 & $\begin{array}{l}1.060- \\
2.382\end{array}$ & $0.025^{\star}$ & 776 & & 1.341 & $\begin{array}{l}0.971- \\
1.851\end{array}$ & 0.075 \\
\hline & Always & 145 & 43.0 & 0.690 & $\begin{array}{l}0.361- \\
1.316\end{array}$ & 0.260 & 192 & 57.0 & 1.599 & $\begin{array}{l}0.956- \\
2.673\end{array}$ & 0.073 & 337 & & 1.128 & $\begin{array}{l}0.757- \\
1.681\end{array}$ & 0.553 \\
\hline \multirow{3}{*}{$\begin{array}{l}\text { Pratice } \\
\text { togheter }\end{array}$} & Never & 205 & 37.4 & 1 & & & 343 & 62.6 & 1 & & & 548 & 100 & 1 & & \\
\hline & Sometimes & 288 & 42.0 & 1.034 & $\begin{array}{l}0.661- \\
2.399\end{array}$ & 0.883 & 398 & 58.0 & 1.000 & $\begin{array}{l}0.693- \\
1.445\end{array}$ & 0.998 & 686 & & 1.028 & $\begin{array}{l}0.775- \\
1,363\end{array}$ & 0.848 \\
\hline & Always & 69 & 44.2 & 1.162 & $\begin{array}{c}0.563- \\
1.620\end{array}$ & 0.685 & 87 & 55.8 & 0.709 & $\begin{array}{l}0.398- \\
1.261\end{array}$ & 0.242 & 156 & & 0.934 & $\begin{array}{l}0.596- \\
1,463\end{array}$ & 0.765 \\
\hline Transport & Never & 268 & 40.5 & 1 & & & 394 & 59.5 & 1 & & & 662 & 100 & 1 & & \\
\hline
\end{tabular}




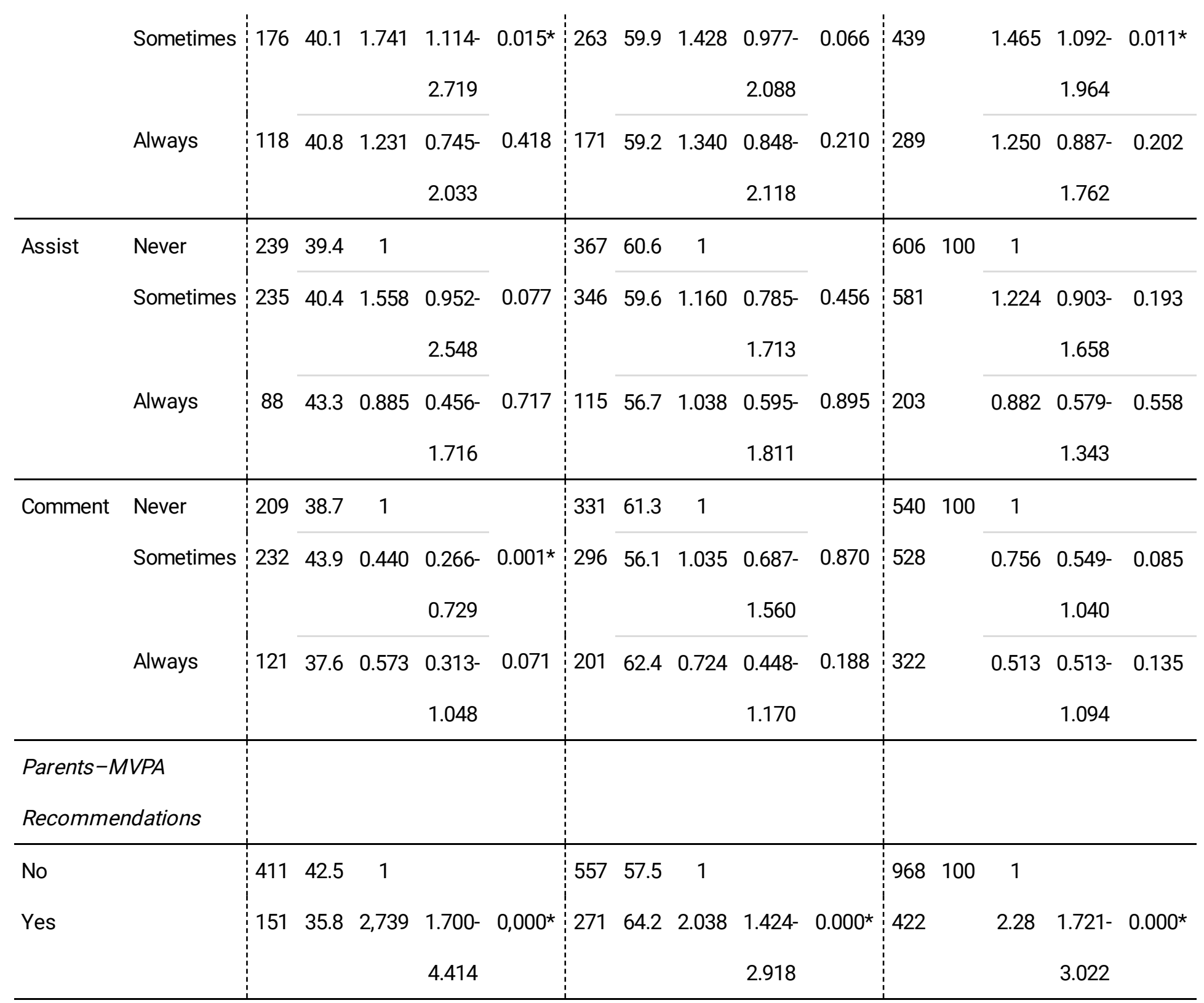

SS: Social Support; MVPA: moderate to vigorous physical activity; *Statistically significant for the test; $p<0,05$. 